\title{
Gender Differences in Factors Influencing Pursuit of Computer Science and Related Fields
}

\author{
Jennifer Wang \\ Google Inc. \\ 1600 Amphitheatre Pkwy \\ Mountain View, CA 94043 \\ +1-310-866-3258 \\ jennifertwang@google.com
}

\author{
Hai Hong \\ Google Inc. \\ 1600 Amphitheatre Pkwy \\ Mountain View, CA 94043 \\ +1-310-866-3258 \\ haihong@google.com
}

\author{
Jason Ravitz \\ Google Inc. \\ 1600 Amphitheatre Pkwy \\ Mountain View, CA 94043 \\ +1-310-866-3258 \\ ravitz@google.com
}

\author{
Marielena Ivory \\ Google Inc. \\ 1600 Amphitheatre Pkwy \\ Mountain View, CA 94043 \\ +1-310-866-3258 \\ mivory@google.com
}

\begin{abstract}
Increasing women's participation in computer science is a critical workforce and equity concern. The technology industry has committed to reversing negative trends for women in computer science as well as engineering and information technology "computing" fields. Building on previously published research, this paper identifies factors that influence young women's decisions to pursue computer science-related degrees and the ways in which these factors differ for young men. It is based on a survey of 1,739 high school students and recent college graduates. Results identified encouragement and exposure as the leading factors influencing this critical choice for women, while the influence of these factors is different for men. In particular, the influence of family is found to play a critical role in encouragement and exposure, and outreach efforts should focus on ways to engage parents.
\end{abstract}

\section{Categories and Subject Descriptors}

K.3.2 [Computers and Education]: Computer and Information Science Education - computer science education.

\section{Keywords}

Gender differences; factors; high school; college; encouragement, perceptions; self-confidence; K-12 education.

\section{INTRODUCTION}

Previous studies that examined the factors that motivate students to pursue studies or careers in technology typically: 1) had small sample sizes, 2) were conducted with students from a particular institution or geographic region, and 3) measured 2-3 independent variables. Our study: 1) surveyed 1,739 young men and women, 2) used a nationally-representative population, 3) considered 91 variables identified in the literature, 4) grouped these into factor scores, and 5) controlled for all significant variables in our analysis. Our analyses allowed us to rank the influence of each variable on young women's decisions to study computer science (CS), along with engineering or information technology (IT) fields. Social encouragement was determined to be one of the most powerful influencers on the decision to pursue these fields - considerably stronger for women than for men. This paper focuses specifically on gender differences in the way such factors influence the decision to pursue computing and related fields.

Permission to make digital or hard copies of part or all of this work for personal or classroom use is granted without fee provided that copies are not made or distributed for profit or commercial advantage and that copies bear this notice and the full citation on the first page. Copyrights for third-party components of this work must be honored. For all other uses, contact the Owner/Author.

Copyright is held by the owner/author(s)

ITICSE '15, Jul 04-08, 2015, Vilnius, Lithuania

ACM 978-1-4503-3440-2/15/07.

http://dx.doi.org/10.1145/2729094.2742611

\section{RELEVANCE}

According to the National Science Foundation [16] Science and Engineering Indicators, women make up only $26 \%$ of Computer Science and Mathematical Science professionals in the United States. These numbers are even more stark when considering that while degree conferment for the proportion of women in science, technology, engineering and mathematics (STEM) is trending upward, the proportion of women in computer science, specifically, has declined to $18 \%$ from a $37 \%$ peak in the mid-1980s [17]. In addition to issues related to equity and workplace diversity, the lack of female participation in computer science exacerbates a problem with labor supply shortages: the overall need for computing professionals has severely outstripped the number of graduates entering the workforce [16]. Moreover, evidence has shown that more diverse teams produce better products. Page [19], for example, found that when solving complex problems, diversity of skills, perspectives, and abilities leads to a better outcome. This has further motivated industry to officially address its lack of diversity.

A wealth of research has investigated factors that influence girls' interest in STEM and CS (e.g., [8,11]). Studies on gender differences showed that women more often ranked their most important life goal as "helping other people" [3], which may be an important influence for girls. Societal influences include a lack of female STEM characters in television and pop culture [2], negative stereotypes about girls' abilities, and negative perceptions about computing as a course of study or career option (e.g., [4]). Parental encouragement to study science and mathematics increases the likelihood of a young adult pursuing [7] and persisting in STEM careers [6]. However, parents' evaluation of their children's abilities differs by gender-in particular, this translates to differences by child gender in parents' perceptions and encouragement of their child's interest in STEM fields (e.g., [5]). Families purchase more STEM games or manipulative materials for boys than for girls [13], and parents of boys believe that their children like science more than parents of girls, more often overestimating their child's science ability than do parents of girls [5].

Girls can develop more positive perceptions of CS-related fields if they receive encouragement at home $[12,15]$. In a survey of scientists, Sonnert [21] found that women were more likely than men to mention a parent as an influencer, and that fathers were more often cited as influencers than mothers were.

\section{DATA SOURCES}

To ensure a statistically relevant study with a high level of confidence $(95 \%$ or better) and a small margin of error $(5 \%$ or less), 1090 young women and 649 young men were surveyed in accordance with the following: 


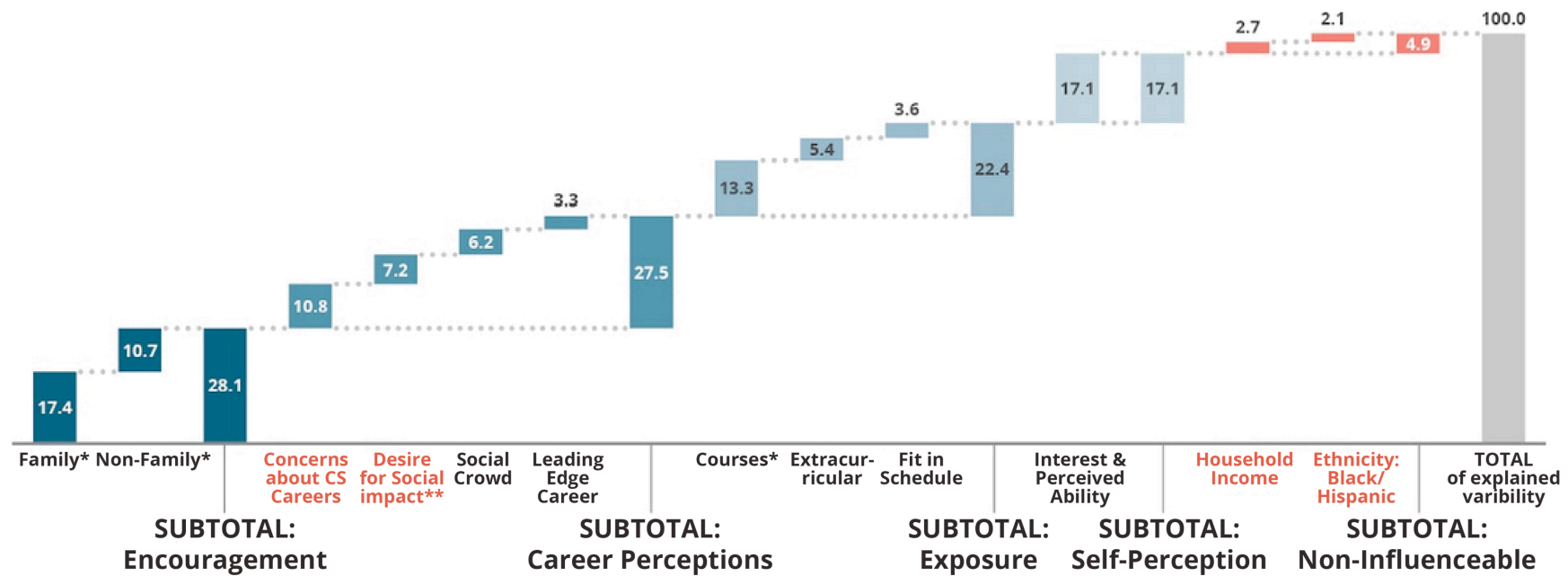

Figure 1. High school model for percentage contribution of factors influencing a girl's choice to study computer science and related fields $(n=527$, Pseudo-R2 $=60.5 \%$, * significantly more influential for girls than boys, $* *$ significantly more influential for boys than girls).

- Geographically and academically diverse, across the US

- $50 \%$ high school, $50 \%$ recent college graduates

- $50 \%$ interested in or had studied a computing-related field

\section{METHODS}

As a first step, we reviewed existing studies in order to: a) determine a comprehensive set of influencing variables, b) identify strengths and limitations and incorporate best practices from previous studies, and c) refine our study's hypothesis around influencing variables. Our review resulted in 91 statistically relevant variables with the potential to influence a decision to pursue a computer science or related mathematics, IT or engineering degree.

The survey was developed to measure the 91 variables' influence on the dependent variable: interest in studying CS and related fields or not. The survey was given online to participants.

Participants were initially recruited via Research Now and their partners' panels of high school juniors and seniors and recent college graduates. To supplement low response rates on the panels $(<5 \%)$, particularly from high schoolers and men, river sampling was used to solicit participants via online banner ads with incentives and snowball referrals with small monetary incentives were used by asking respondents to refer others, particularly computer science women. Women and those interested in or who had studied computer science were oversampled for this study. To obtain a nationally-representative sample, quotas for age and gender were used and data on ethnicity and geographical region were weighted after data collection.

Using factor analysis [10], all 91 variables were combined into 25 factors used concurrently to control for highly correlated variables. To control for related influences and fairly evaluate competing factors, the survey results were analyzed using logit regression - a form of statistical modeling used to predict binary outcomes [1]. We used logit regression to rate the importance of factors in predicting interest in pursuing the computing-related fields. We used this analysis to measure the strength of the relationship between dependent variables (wanting to pursue a CS-related degree) and independent variables (e.g., the life experiences and opportunities that may lead to that choice).

\section{RESULTS}

Results suggest the high school model for girls' influencers has a very high Pseudo-R2, as shown in Figure 1. The influencing factors contribute to $60.5 \%$ of the dependent variable - an exceptionally high score that translates to reasonably accurate influence modeling. Our study found that encouragement and exposure are key controllable indicators for whether or not young women decide to pursue a computing-related degree. The top four influencing factors for young women-and notable gender differences related to these factors-were as follows:

\subsection{Social Encouragement}

Social encouragement includes positive reinforcement from family, teachers, and peers, and for the high school model, comprises $28.1 \%$ of the explainable factors influencing a young woman's wanting to pursue a computing-related degree. Encountering this encouragement in an extracurricular setting also has a large impact. Our findings suggest encouragement from non-family $(11 \%)$ is almost as important as familial support (17\%) for young women (see Figure 2). Overall, encouragement from family (parents and siblings) as well as from non-family (teachers, role models, peers, and media) contributed significantly more to girls' decisions to pursue a computing-related degree when compared to boys.

Figure 3 shows that, across the various types of social encouragement, CS girls were most likely to be encouraged by their mother, father, sibling, teacher, or friends and peers. On the other hand, non-CS girls were least likely to receive encouragement from all except their teacher. And, of particular note is the discrepancy within genders: the discrepancy between encouragement received for CS girls and for non-CS girls was much larger compared to the discrepancy between encouragement for CS boys and for non-CS boys. In other words, of those who were not interested in CS-related fields, boys were more likely to be encouraged while of those who were interested in CS-related fields, girls were more likely to be encouraged.

For both the high school and the college model, the occupation of parents was statistically insignificant when controlling for other variables. Although parents with computing backgrounds may offer more encouragement, what seems to matter most is encouragement, not whether this encouragement was from someone with technical expertise. This is particularly important since even though encouragement is much more important to young women than to young men (Figure 2), young women are less likely than young men to receive that encouragement (in any form). Furthermore, while encouragement from family is the most 
High school model

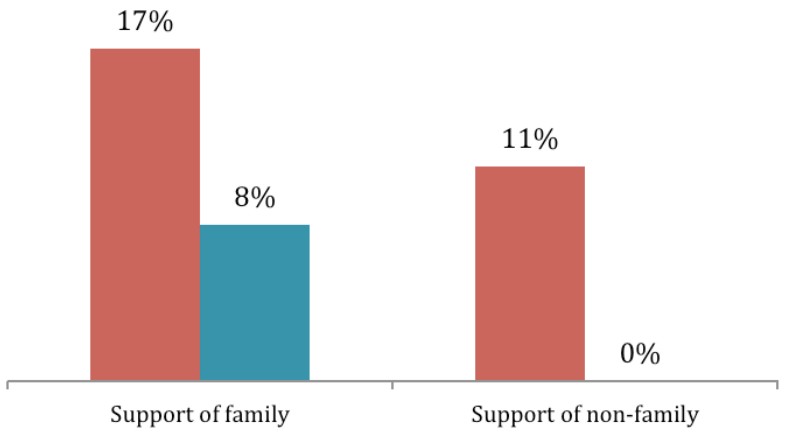

College model

Girls

Boys

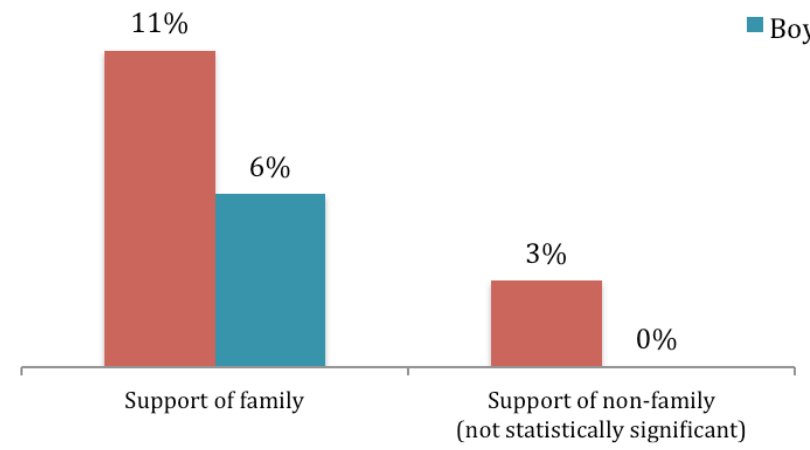

Figure 2. Total percentage contribution to choosing to study computer science of the variables support of family and support of non-family for males and females $\left(n=846\right.$ for high school and $n=893$ for college, Nagelkerke $\left.R^{2}=\mathbf{5 6 . 8 \%}\right)$.

influential variable overall and is more important for young women than for young men $(17 \%$ vs. $8 \%)$, there is an even larger discrepancy in the influence of encouragement received from nonfamily members ( $11 \%$ for females vs. $0 \%$ for males; Figure 2$)$.

Figure 4 shows the differences in parent encouragement received for both women and men college graduates. Not surprisingly, most CS graduates received encouragement from parents. However, of the non-CS graduates, only $12 \%$ of women vs. $21 \%$ of men received encouragement from mothers, and similarly, only $19 \%$ of women vs. $30 \%$ of men received encouragement from fathers. As discussed above for high school students, similar discrepancies were found for those not interested in computer science and related fields. Thus, of those interested in $\mathrm{CS}$, more girls are encouraged than boys while of those not interested in CS, more boys are encouraged than girls, and our analyses show that encouragement is a highly influential factor for girls (Figure 1).

The major takeaway is that efforts to increase girls' interest in computing should include a parent education component, so that they know how to actively encourage their daughters. Parents who are not in technology fields need to know that their words and actions have an impact, and should feel confident encouraging their daughters to try out computing.

\subsection{Career Perceptions}

Another key finding concerns the familiarity with and perception of computing as having diverse applications and a broad potential for positive societal impact. At 27.5\%, a high school girl's perception of computer science and its associated careers is the second most potent explainable factor influencing the pursuit of a computer science degree.

Specifically, interest in a career with social impact was negatively influential for both boys and girls, but significantly more influential for boys than girls at the pre-college level. This

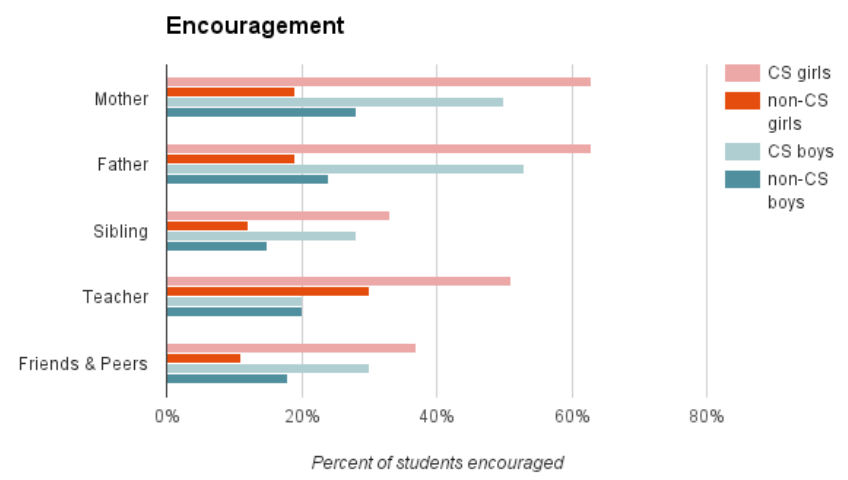

Figure 3. Percent of high school students encouraged, by gender and interest in CS-related fields $(n=846)$.

means that boys are significantly more likely to not want to study CS-related fields than girls if they were interested in a career with social impact. On the other hand, the social crowd in CS courses was significant only for girls, steering girls away from CS if the social crowd was not like them. And, of the college graduates population, $44 \%$ of young women who majored in computer science believed that first year computer science courses were geared towards male interests.

Furthermore, perceptions from role models is a much stronger influencer for women than for men, as shown in Figure 5. Of the college graduates, more women CS majors strongly agree that "Role models gave me a good impression of CS" than men CS majors. On the other hand, many more women non-CS majors strongly disagreed with the statement, even compared to men nonCS majors. Thus, women may be more strongly impacted than men by role models in the field.

The negative potential associated with flawed or incomplete career perceptions is twofold: 1) not understanding computing fields makes an informed decision more difficult and, 2) an incomplete perception of the discipline actively dissuades young women from considering it. The end result is that young women unfamiliar with computer science and its broad applications have difficulty visualizing it outside the narrow scope often presented in popular media. They may be unable to perceive computer science-related careers as fulfilling both the academic passion (inventing, problem solving, exploration, etc.) and the intangible,
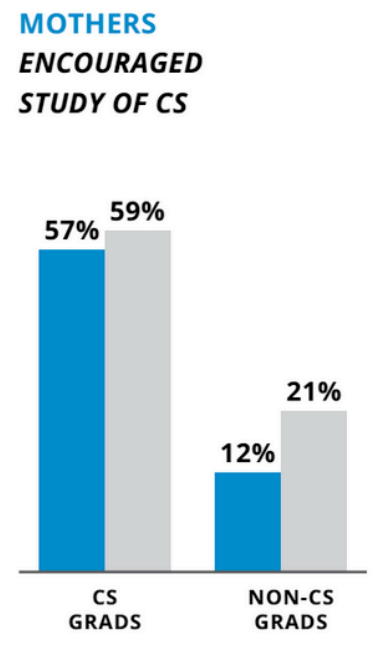

FATHERS

ENCOURAGED STUDY OF CS

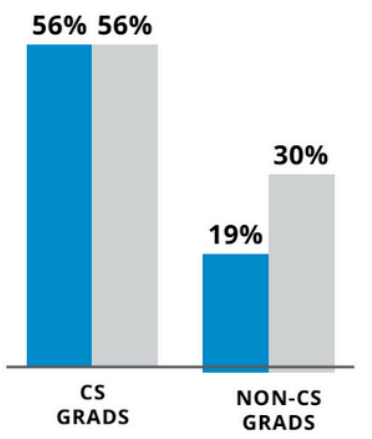

FEMALES

Figure 4. Percent of college grads whose parents encouraged study of computer science $(n=893)$. 


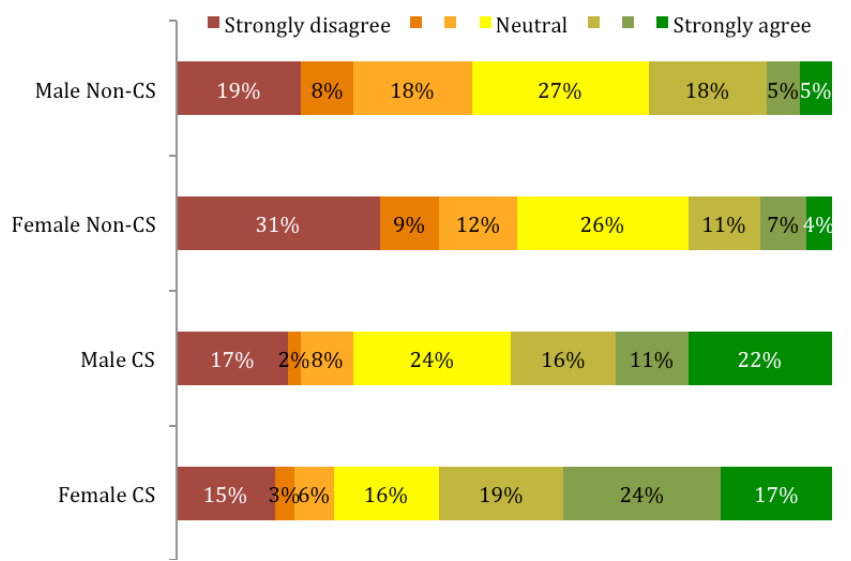

Figure 5. Percent of college grads and their agreement with the statement "Role models gave me a good impression of CS" $(n=893)$.

social passions (helping people, conservation, medical breakthroughs, etc.) that make a profession personally rewarding. Thus, limited and negative perceptions around what CS involves and who does CS narrow participation in the field. It is important to show the broad applications of CS as well as diverse computer scientists.

\subsection{Academic Exposure}

The ability to participate in computer science courses and activities accounts for $22.4 \%$ of the explainable factors influencing whether girls say they want to pursue a computer science-related degree. This includes participation in structured (e.g., graded studies) and unstructured (e.g., after-school programs) activities.

Importantly, having taken a CS course before college plays a significantly larger role for girls than boys in choosing to study CS-related fields. And, influential factors for high school girls only included logistical and social aspects of participation; scheduling issues and courses not counting for requirements as well as lack of friends in the courses influenced girls to not take CS courses. Thus, exposure, utility, and broad participation in CS courses may be key for increasing the number of girls pursuing computer science.

Among the college population, those who had the opportunity to take the Advanced Placement (AP) Computer Science A exam
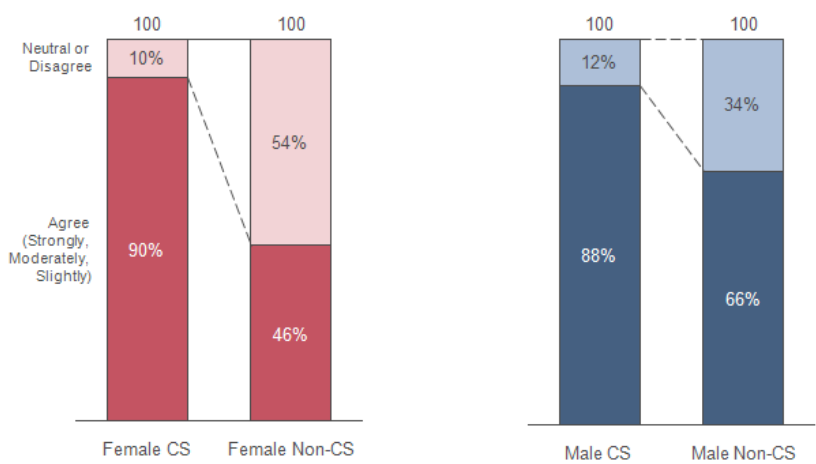

Figure 7. College graduates' agreement with the statement "I think I understand the difference between computer science and IT" $(n=893)$. Note the discrepancy between females and males in the non-CS group.

were $46 \%$ more likely to pursue a computing major. This is particularly true for women, who are $38 \%$ more likely to pursue a computing degree after having taken AP Computer Science in high school. Yet, in high school, girls interested in computer science most often cite not having space in their schedules or classes being full as reasons for not having taken computer science.

In addition to examining the influence of AP coursework specifically, the study controlled for varying high school curricula (e.g., no computer science classes, compulsory classes, and elective classes) and the accessibility of extra-curricular programs (e.g., clubs and camps) and found that, regardless of how they were exposed, young women who had opportunities to engage in learning about computer science were more likely to consider computing-related degrees than those without those opportunities.

Furthermore, among college graduates who did not major in $\mathrm{CS}$, a larger percentage of women than men were not able to recall the availability of CS classes (AP and non-AP), extracurricular CS classes, extracurricular CS clubs, and CS camps (see Figure 6). This shows that there is a greater lack of awareness of CS opportunities among women when compared to men. Following this, Figure 7 shows that of those who did not major in CS, a larger percentage of women than men indicated that they disagreed that they understood the difference between IT and CS, while a larger percentage of men than women in CS indicated that they strongly agreed with the statement.
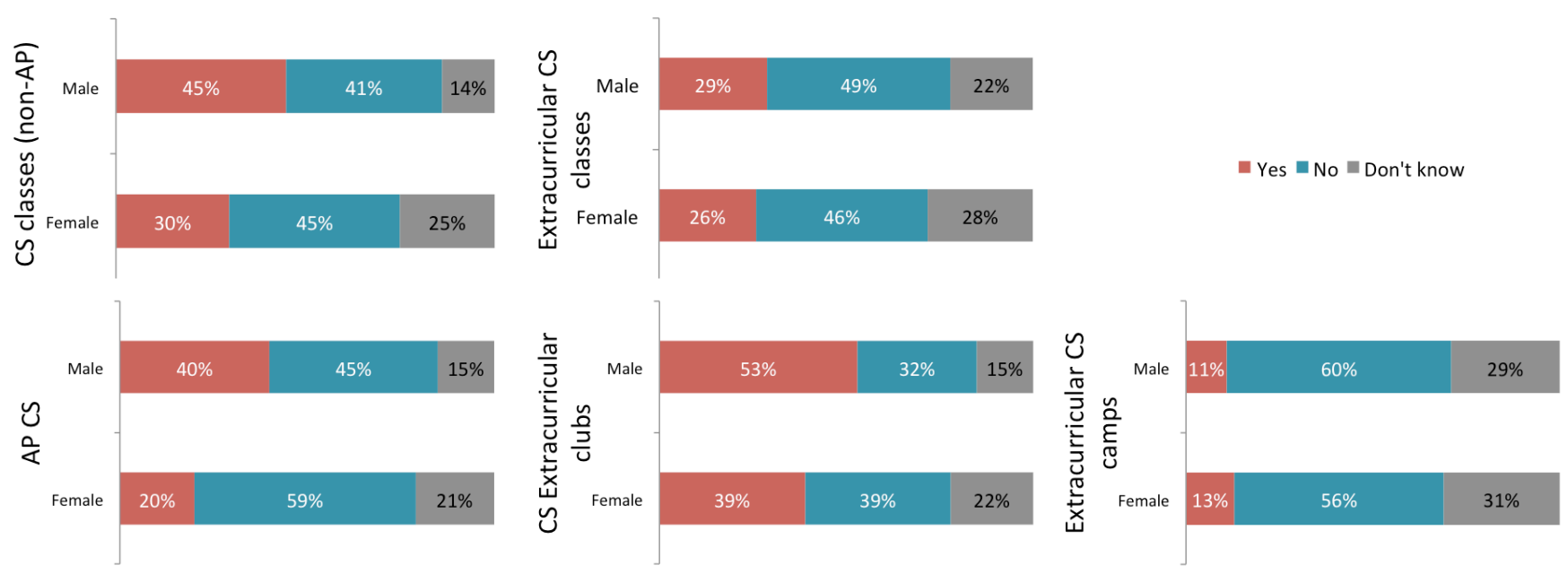

Figure 6. Non-computer science major college graduates' recall of availability of computer science opportunities in high school $(\mathbf{n}=\mathbf{8 9 3})$. 

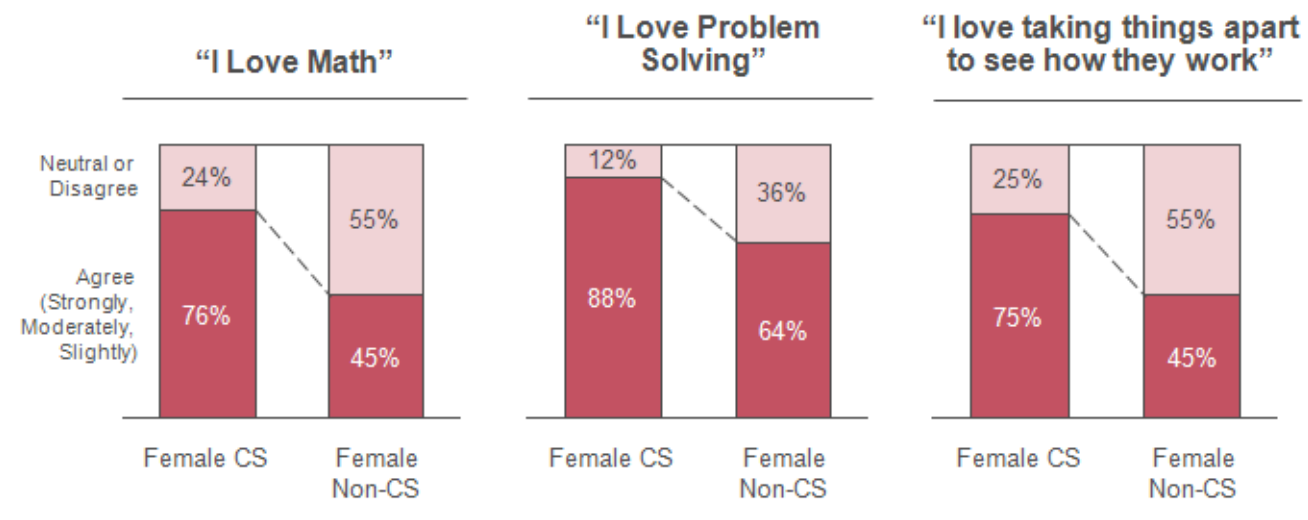
see how they work
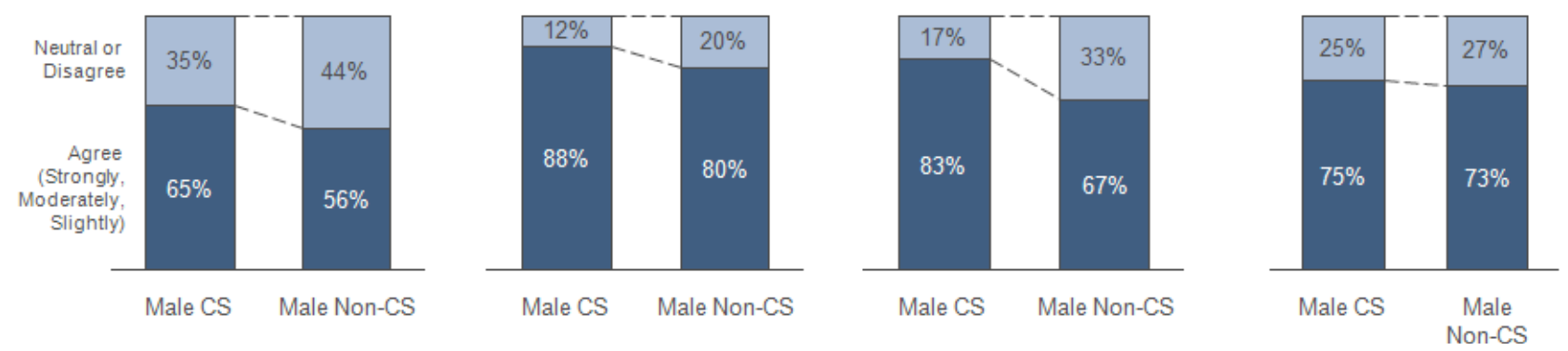

Figure 8. College graduates' agreement with various statement about their interests and personalities $(n=893)$. The discrepancy between CS and non-CS females is often greater than the discrepancy between CS and non-CS males.

We also found that scholarships for studying CS were significantly more influential for women than men. This provides an important practical implication that offering scholarships to women is a means of broadening awareness, exposure, and participation.

The key takeaway is that the specific type of participation is statistically insignificant when measured against having been exposed in some way. This seems to be a case of "anything is better than nothing." Early exposure to computer science is important because familiarity with a subject can generate interest and curiosity while establishing a sense of competency. Moreover, even a basic understanding of computing provides insight into viable career paths within the field and how those careers can be leveraged to achieve personal goals. Increasing awareness through exposure, encouragement, and support can help provide a broader and more complete picture of computer science as relevant to girls' lives and help widen participation.

\subsection{Self-Perception}

Finally, girls' interest in and perceptions of their own proficiency in mathematics and problem-solving significantly influence their wanting to pursue a computing-related education. In the high school model, this perception comprises $17.1 \%$ of the explainable factors. No significant differences in this factor were found between girls and boys, though of high schoolers interested in CS and related fields, girls were more likely than boys ( $81 \%$ vs $66 \%$ ) to agree that they were "always in the top or 'honors' math classes." Among college students who had studied CS, women were significantly more likely than men (76\% vs. $65 \%)$ to agree with the statement "I love math" (see Figure 8).

This positive self-perception provides internal encouragement in the form of ongoing confidence in one's abilities. Families and educators can foster positive self-perception by encouraging interest in mathematics and tinkering and creating safe opportunities for girls to explore and build these skills.

The high influence of self-perceptions confirms previous studies on the influence of self-confidence on students' persistence, career interests, etc. (e.g., [9,14,18,20,23]), which have shown that girls usually have lower self-confidence than boys. As a consequence, girls' lower confidence discourages them from pursuing these fields. Furthermore, encouragement has been found to help increase confidence [22], and shows the interrelatedness of the various influencing factors. Thus, selfperception is a key factor in choosing to study CS for both genders, with interest and confidence in technical subjects potentially more influential for girls.

\section{SIGNIFICANCE}

Our study addresses a major societal issue that speaks to the concerns of advocates for women and workforce development. Our findings offer actionable recommendations by identifying the top factors influencing women to study computing fields.

The study found most of the decision-making to pursue computer science-related fields, including engineering and IT, occurs before a young woman begins college; once she enters college, application requirements and variable interdependence are so tightly coupled that the decision becomes less malleable. As a result, the factors with the most influence are associated with pre-college experiences.

The most heartening outcome of the study is the limited role that uncontrollable factors play in influencing the pursuit of a computer science degree. For example, for high school girls, uncontrollable factors like household income and ethnicity contribute to only $4.9 \%$ of the explainable factors-statistically insignificant when compared to factors that can be controlled. Not only do uncontrollable factors play a limited role in explaining a young woman's decision to pursue a computer science-related degree, the controllable factors of encouragement and exposure are the largest influencers.

Exposure to and the ability to enroll in computer science courses in- or out-of-school are critical to girls pursuing CS in college. Encountering encouragement in an extracurricular setting may have a large impact because it fosters peer encouragement and places computing in a social context. Accordingly, parents 
have a key role to play in giving girls the experience and confidence to pursue interests in these fields-either by advocating for computer science and related classes in their children's schools or by identifying opportunities in the local community (or online) to explore their learning. Parents and families can foster positive self-perception by encouraging interest in mathematics and tinkering and creating safe opportunities for girls to explore and build these skills.

Our research suggests it is important to help parents and educators learn how to draw attention to the wide applicability of computing to a variety of fields. The negative potential associated with flawed or incomplete career perceptions is two-fold: 1) not understanding computing fields makes an informed decision more difficult and 2) an incomplete perception can actively dissuade young women from considering one of these fields. The end result is that young women unfamiliar with computer science and its broad applications may have difficulty visualizing it outside the narrow scope often presented in popular media. They may be unable to perceive computer science-related careers as fulfilling both the academic passion (inventing, problem solving, exploration, etc.) and the intangible, social passions (helping people, conservation, medical breakthroughs, etc.) that make a profession personally rewarding.

The bottom line is that the factors most related to female participation in computing are actionable, and understanding the differences between the way such factors influence men and women will help inform our approaches to taking action. That's not to say this is a problem that can be solved easily, but it is a problem that can be tackled with deliberate and directed action focused on encouragement and exposure.

\section{ACKNOWLEDGEMENTS}

We acknowledge the contributions of our colleagues: Iveta Brigis, Sarah Chavis, Heather Thorne, Eduardo Samuel, and others. We also thank Applied Marketing Science for assistance with instrument development, data collection, and analyses.

\section{REFERENCES}

[1] Anderson, J. A. (1982). Logistic regression. Handbook of Statistics. North-Holland, New York, 169-191. Retrieved from http://www.schatz.sju.edu/multivar/guide/Logistic.pdf

[2] Achtenhagen, L., Johansson, A., \& Picard, R. (2007). The Promotion of Entrepreneurship in the Audio-Visual Media (esp. TV): Final Report for the European Commission, Enterprise and Industry Directorate-General. Retrieved from http://ec.europa.eu/enterprise/policies/sme/files/support_mea sures/av/media_study_en.pdf

[3] Barth, J., Todd, B., Goldston, D., \& Guadagno, R. (2010). An Integrated Approach to Choosing Technical Careers: Gender Differences in Life Goals for College Students.

[4] Benyo, J., \& White, J. (2009). New Image for Computing: Report on Market Research. Boston, MA: WGBH Educational Foundation and the Association for Computing Machinery. Retrieved from http://www.zephoria.org/files/NICReport.pdf

[5] Bhanot, R.T. \& Jovanovic, J. (2009). The Links Between Parent Behaviors and Boys' and Girls' Science Achievement Beliefs. Applied Developmental Science. Philadelphia, PA. 42-59.

[6] Dabney, K. P., Chakraverty, D., \& Tai, R. H. (2013). The Association of Family Influence and Initial Interest in Science. Science Education, 97(3), 395-409.
[7] Fan, X. \& Chen, M. (2001). Parental Involvement and Students' Academic Achievement: A Meta-Analysis. Retrieved from http://rd.springer.com/article/10.1023/A:1009048817385

[8] Fisher, A., \& Margolis, J. (2002). Unlocking the Clubhouse: the Carnegie Mellon Experience. ACM SIGCSE Bulletin, 34(2), 79-83. Retrieved from http://dl.acm.org/citation.cfm?id=543836

[9] Fox, M. F., \& Firebaugh, G. (1992). Confidence in Science: The Gender Gap. Social Science Quarterly.

[10] H. H. Harman. (1976). Modern factor analysis. Chicago, IL: University of Chicago Press.

[11] Hill, C., Corbett, C., \& St Rose, A. (2010). Why So Few? Women in Science, Technology, Engineering, and Mathematics. Washington, DC: American Association of University Women. Retrieved from http://files.eric.ed.gov/fulltext/ED509653.pdf

[12] Ing, M. (2014). Can Parents Influence Children's Mathematics Achievement and Persistence in STEM Careers?. Journal of Career Development, 41(2), 87-103. Retrieved from http://jcd.sagepub.com/content/41/2/87

[13] Jacobs, J. E., \& Bleeker, M. M. (2004). Girls' and Boys' Developing Interests in Math and Science: Do Parents Matter? New Directions for Child and Adolescent Development. 5-21.

[14] Lent, R. W., Brown, S. D., \& Larkin, K. C. (1986). Selfefficacy in the Prediction of Academic Performance and Perceived Career Options. Journal of Counseling Psychology, 33(3), 265.

[15] Miller, J. D., \& Kimmel, L. G. (2012). Pathways to a STEMM Profession. Peabody Journal of Education, 87(1), 26-45.

[16] National Science Foundation. (2012). Science and Engineering Indicators 2012. Washington, DC. Retrieved from http://www.nsf.gov/statistics/seind12/c0/c0i.htm

[17] National Center for Education Statistics (2012). Degrees conferred by degree-granting institutions. Washington, DC. Retrieved from http://nces.ed.gov/programs/digest/d12/tables/dt12_318.asp

[18] O'brien, V., Martinez-Pons, M., \& Kopala, M. (1999). Mathematics Self-efficacy, Ethnic Identity, Gender, and Career Interests Related to Mathematics and Science. The Journal of Educational Research, 92(4), 231-235.

[19] Page, S. E. (2008). The Difference: How the Power of Diversity Creates Better Groups, Firms, Schools, and Societies. Princeton University Press.

[20] Shashaani, L. (1994). Gender-differences in Computer Experience and Its Influence on Computer Attitudes. Journal of Educational Computing Research, 11(4), 347-367.

[21] Sonnert, G. (2009). Parents Who Influence Their Children to Become Scientists: Effects of Gender and Parental Education. Social Studies of Science. 927-941. Retrieved from http://sss.sagepub.com/content/39/6/927

[22] Stake, J. E. (2006). The Critical Mediating Role of Social Encouragement for Science Motivation and Confidence Among High School Girls and Boys. Journal of Applied Social Psychology, 36(4), 1017-1045.

[23] Wilson, B. C. (2002). A Study of Factors Promoting Success in Computer Science including Gender Differences. Computer Science Education, 12(1-2), 141-164. 